\title{
A surface water flooding impact library for flood risk assessment
}

\author{
Timothy Aldridge ${ }^{1, a}$, Oliver Gunawan ${ }^{1}$, Robert J. Moore ${ }^{2}$, Steven J. Cole ${ }^{2}$, and David Price ${ }^{3}$ \\ ${ }^{1}$ Health and Safety Laboratory, Buxton, SK17 9JN, UK \\ ${ }^{2}$ Centre for Ecology \& Hydrology, Wallingford, OX10 8BB, UK \\ ${ }^{3}$ Flood Forecasting Centre, Met Office, Exeter, EX1 3PB, UK \\ (C) British Crown Copyright, 2016
}

\begin{abstract}
The growing demand for improved risk-based Surface Water Flooding (SWF) warning systems is evident in EU directives and in the UK Government's Pitt Review of the 2007 summer floods. This paper presents a novel approach for collating receptor and vulnerability datasets via the concept of an Impact Library, developed by the Health and Safety Laboratory as a depository of pre-calculated impact information on SWF risk for use in a real-time SWF Hazard Impact Model (HIM). This has potential benefits for the Flood Forecasting Centre (FFC) as the organisation responsible for the issuing of flood guidance information for England and Wales. The SWF HIM takes a pixel-based approach to link probabilistic surface water runoff forecasts produced by CEH's Grid-to-Grid hydrological model with Impact Library information to generate impact assessments. These are combined to estimate flood risk as a combination of impact severity and forecast likelihood, at $1 \mathrm{~km}$ pixel level, and summarised for counties and local authorities. The SWF HIM takes advantage of recent advances in operational ensemble forecasting of rainfall by the Met Office and of SWF by the Environment Agency and CEH working together through the FFC. Results are presented for a case study event which affected the North East of England during 2012. The work has been developed through the UK's Natural Hazards Partnership (NHP), a group of organisations gathered to provide information, research and analysis on natural hazards for civil contingencies, government and responders across the UK.
\end{abstract}

\section{Introduction}

There is a growing demand for improved risk-based surface water flooding (SWF) warning systems. This is evident in EU directive 2007/60/EC [1] which calls for member states to consider both flood hazard and its impacts, and the UK Government's Pitt Review of the summer 2007 floods [2] which makes recommendations for the development of tools and techniques for modelling surface water flooding, including forecasting capabilities. SWF is particularly challenging to predict due to its rapid onset and localised extent [3]. Improvements to prediction of the hazard have been made via numerical weather prediction and probabilistic forecasting [4], but development of research on the potential impacts of flood hazards is still required to provide more targeted information to responders $[5,2]$. Further, Parker et al. [6] add that there is a growing requirement for rapid impact assessments of SWF hazards that can be integrated into an operational environment.
This paper presents a novel approach to impact modelling that takes advantage of updated data and recent developments in numerical weather prediction, hydrological modelling and probabilistic forecasting in an effort to provide more targeted information to responders on flood impact and risk alongside information on the flood hazard.

Under the banner of the Natural Hazards Partnership (NHP), work commissioned by the Flood Forecasting Centre (FFC) has led to the development of a proof-ofconcept SWF Hazard Impact Model (HIM). Work on the SWF HIM has been undertaken in collaboration with NHP partners at the Centre for Ecology \& Hydrology $(\mathrm{CEH})$, the FFC, the Health and Safety Laboratory (HSL) and the Environment Agency. The SWF HIM proposed in this paper offers improved spatial detail on surface runoff information and a method of quantifying flood impacts and risk. This is achieved through use of the Grid-to-Grid (G2G) hydrological model - developed by $\mathrm{CEH}[7,3]$ and in use operationally within the FFC for assessment of fluvial flooding [8] - and through creation

\footnotetext{
a Corresponding author: timothy.aldridge@hsl.gsi.gov.uk
} 
of a multi-dimensional pre-calculated Impact Library developed by HSL. This paper details the development of the Impact Library through the novel assimilation of multiple SWF scenarios and a range of categorised receptor information using unique datasets and increased spatial detail. These improvements allow a more disaggregated and focused assessment of the risks to different receptors at county and local scales.

\section{Impact categories and metrics}

As advisors for emergency responders, the FFC are principally interested in the direct, short-term, impacts of flooding. For the SWF HIM, impact categories are selected based on criteria used by the FFC for flood risk assessment, while indicators suggested by the EA for local flood risk assessment [9] provide a starting point for the set of impact metrics used.

Danger to life is a key indicator for flood risk, as evidenced in Vinet et al. [10], which states that the protection of people is viewed as a priority by state actors. Methods of measurement are commonly counts of impacted individuals. Elderly and long-term ill populations are typically assumed to be more vulnerable to flooding than other population members based on an assumption of physical vulnerability to the flood hazard. This follows the Flood Risk to People Methodology developed for the Environment Agency [11].

Buildings represent a major component of the urban landscape and provide shelter to residents, places of employment and services for wider populations [12]. The impacts to buildings from flooding are often measured using economic metrics. For example, Penning-Rowsell et al. [13] have developed the Multi-Coloured Manual (MCM) for comprehensive economic appraisal of UK flood and coastal erosion risk management. However the EA [9] suggest that a property count approach may be a more appropriate requirement for a forecasting tool. This is on the basis that it is more useful for estimating the overall scale of the risk, and assists in the prioritisation of communication to at-risk local communities.

The disruption caused by denial of access to infrastructure, in terms of key sites (schools, hospitals etc.) and networks (transport, utilities etc.) is a common theme that affects the efficiency of emergency response, with further consequences for the economy and disruption of daily life [14]. Infrastructure impacts are included across National Risk Registers and are considered in terms of the compromised ability for an area to service its communities [15]. In particular, energy networks are commonly found to be most critical as they support all other networks through transmission of electricity, gas or other fuels. In this paper, key sites are defined as critical services located within buildings which, if damaged by flood water, might need to close or be reduced to a limited service: for example, a GP surgery, or care home. Infrastructure sites are locations or networks providing utility services that might be adversely affected or inaccessible during a flood event, such as electrical installations or sanitation services.

Disruption of the transport network is an important indicator of flood risk due to the direct and indirect effects on emergency response and evacuation, and longer term traffic disruption and inaccessibility [12].

\section{Implementation}

\subsection{Case study site and event}

The case study site is located in North East England as indicated by the red outline in Figure 1 which is a $150 \mathrm{~km}$ by $150 \mathrm{~km}$ square including the counties/local authorities of Tyne and Wear, Northumberland, County Durham, Darlington, Stockton-on-Tees, Hartlepool, Middlesbrough, and Redcar and Cleveland.

On 27 June 2012, unusually warm and humid air from the continent moved northwards across the UK [16]. This caused significant SWF across Northern Ireland. On 28 June, the emphasis shifted to central, eastern and northern England where severe thunderstorms brought locally torrential rain, large hail and further flooding from surface water and small rivers. In the morning these storms were widespread across the south of the Midlands and the Birmingham area and moved into Cumbria, northeast England and Lincolnshire later in the day. The storms cleared early in the evening of 28 June. The main impacts from these storms were seen in the north of England where hourly rainfall totals of around $30 \mathrm{~mm}$ were recorded in the heavier downpours. Isolated locations experienced $40-50 \mathrm{~mm}$ of rain in two to three hours. The extreme rainfall caused major disruption to infrastructure including the closure of the A1 and many minor roads in the North East. A survey of residents post event by Newcastle City Council [17] found that over 1200 properties were impacted with over 500 being internally flooded.

\subsection{Key Datasets}

\subsubsection{The updated Flood Maps for Surface Water}

The updated Flood Maps for Surface Water (uFMfSW) from the EA are the most up-to-date national scale SWF maps for England and Wales [18]. They detail the worst-case flood extents for defined events based on three rainfall probabilities ( 1 in 30 year, 1 in 100 year and 1 in 1000 year) and three different storm durations (1 hour, 3 hour and 6 hour). The impact library uses summarised maximum depth values for each return period as SWF hazard susceptibility maps, making an assumption of a worst-case scenario. The resolution of the uFMfSW data is $2 \mathrm{~m}$, a level suitable for a microlevel assessment of the flood severity. 


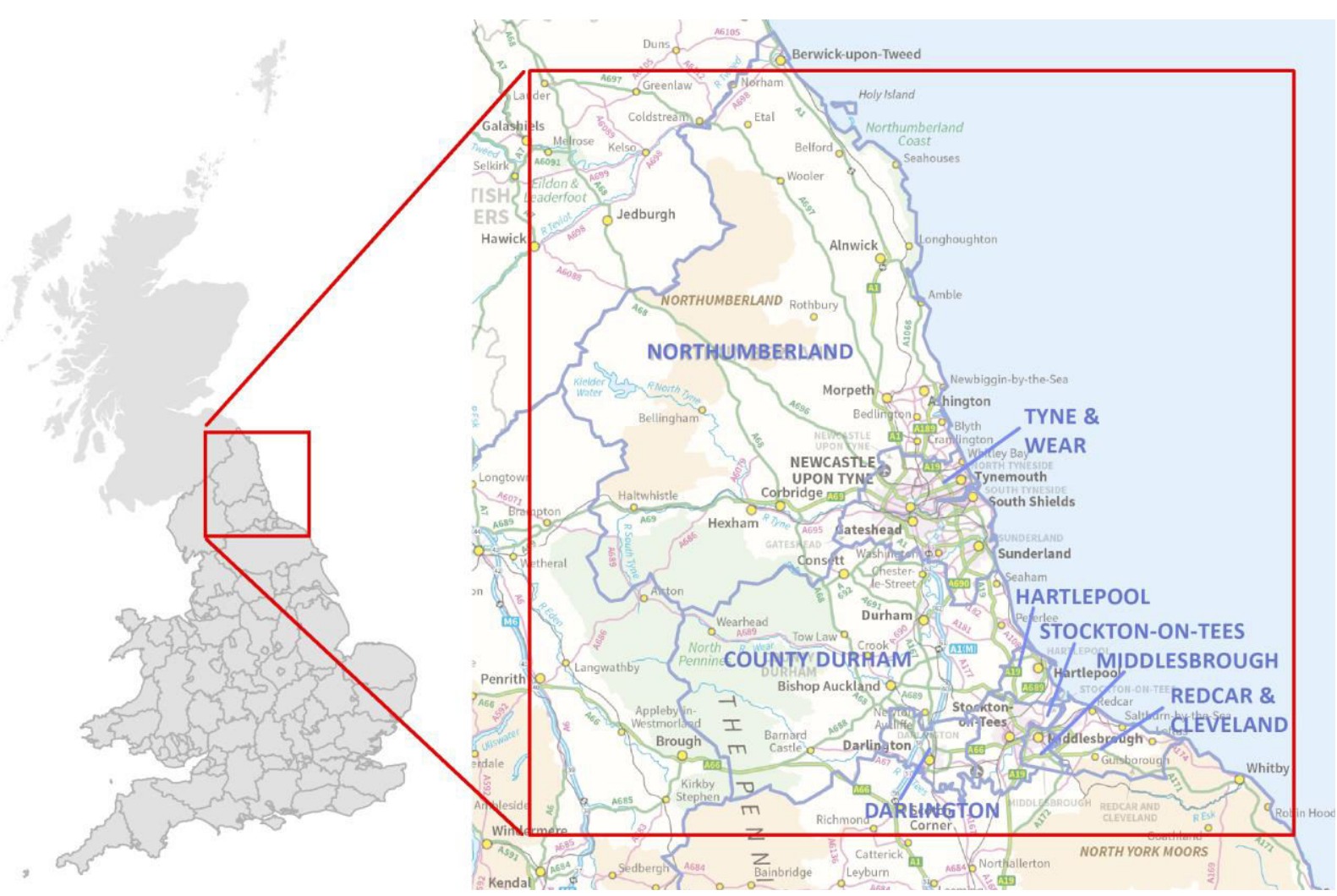

Figure 1. Extent of SWF HIM case study site and reporting areas. Contains OS data $\odot$ Crown copyright and database right (2016)

\subsubsection{The National Population Database}

The National Population Database (NPD) models the location and scale of different population groups in the UK using an approach that can be used for local or national estimates in a consistent way [19]. It was originally developed to support the Health and Safety Executive in its regulation of major hazard installations but has since been used in wider contexts including evaluation of SWF risk [3]. The NPD combines population and attribute information from a range of sources including government datasets and the UK census, attaching them to Ordnance Survey location data (AddressBase, ITN, CodePoint) for spatial analysis. The population layers are organised into five themes: Residential, Workplace, Sensitive, Transport and Leisure. The population layers can be organised and combined into different temporal scenarios including day time and night time.

\subsubsection{The National Receptor Dataset}

The National Receptors Dataset (NRD) is a collection of risk receptors produced by the EA [20]. It is primarily intended for use in flood and coastal erosion risk management and was developed to evaluate flood damage at the regional or national scale. Version 1 of the NRD property point data uses Ordnance Survey (OS) datasets AddressLayer 2 and MasterMap to provide information on every property in England and Wales that has a corresponding record in AddressLayer 2 (which includes addressable and non-addressable locations), or has a footprint greater than $25 \mathrm{~m}^{2}$. For this study, version 1 of the NRD (released 2010) was used. The building information in the NRD includes classifications for the Multi-Coloured Manual [13], which can be used further to flag infrastructure and determine residential property type and non-residential building use.

\subsection{Impact criteria measurements}

The impact criteria are outlined in Table 1. Danger to life impacts were evaluated as the number of people at risk, based on a sum of NPD population estimates at locations that exceed hazard rating thresholds when intersected with the uFMfSW data, where the hazard rating is a function of flood depth and velocity. Impacts on population were considered for day time and night time population scenarios based on the NPD configurations outlined in Table 1. Populations more vulnerable to the flood hazard were identified as a subset of the NPD sensitive layers. Populations were deemed at risk if exposed to a flood hazard rating of 1.25 (Significant) or greater, with the exception of the more vulnerable populations which used a hazard rating threshold of 0.75 (Moderate), based on the classifications proposed by HR Wallingford [11]. 


\begin{tabular}{|c|c|c|c|c|}
\hline Criteria & Data & Impact Metric & \multicolumn{2}{|c|}{ Impact criteria detail } \\
\hline \multirow[t]{2}{*}{ Danger to Life } & \multirow[t]{2}{*}{ NPD } & \multirow[t]{2}{*}{ Count of people at risk } & $\begin{array}{l}\text { Day time } \\
\text { population: }\end{array}$ & $\begin{array}{l}\text { Day time term-time Residential } \\
\text { Workplaces } \\
\text { Schools/Care Homes } \\
\text { Hospitals/Prisons }\end{array}$ \\
\hline & & & $\begin{array}{l}\text { Night time } \\
\text { population: }\end{array}$ & $\begin{array}{l}\text { Night time term-time Residential } \\
\text { Care Homes } \\
\text { Hospitals/Prisons }\end{array}$ \\
\hline \multirow[t]{2}{*}{ Damage to Buildings } & \multirow[t]{2}{*}{ NRD } & \multirow[t]{2}{*}{ Count of properties at risk } & \multicolumn{2}{|c|}{ Residential properties } \\
\hline & & & \multicolumn{2}{|c|}{ Non-residential properties } \\
\hline \multirow[t]{2}{*}{$\begin{array}{l}\text { Denial of access to } \\
\text { key sites/ } \\
\text { infrastructure }\end{array}$} & \multirow[t]{2}{*}{ NRD } & \multirow[t]{2}{*}{ Count of sites at risk } & Key sites & $\begin{array}{l}\text { Schools/Colleges/Universities } \\
\text { Surgeries/Health Centres } \\
\text { Residential home } \\
\text { Fire/Ambulance/Police Stations } \\
\text { Hospitals }\end{array}$ \\
\hline & & & Infrastructure & $\begin{array}{l}\text { Electrical installations } \\
\text { Gas regulating facilities } \\
\text { Water treatment works }\end{array}$ \\
\hline \multirow{3}{*}{$\begin{array}{l}\text { Denial of access to } \\
\text { transport networks }\end{array}$} & \multirow[t]{3}{*}{ NRD } & \multirow{3}{*}{$\begin{array}{l}\text { Length of network at risk } \\
\text { (m) }\end{array}$} & \multicolumn{2}{|l|}{ Trunk roads } \\
\hline & & & \multicolumn{2}{|c|}{ Non-trunk A/B road } \\
\hline & & & \multicolumn{2}{|l|}{ Railway } \\
\hline
\end{tabular}

Table 1. Impact metrics stored in the SWF Impact Library.

Damage to buildings was assessed using a flood depth threshold to estimate numbers of buildings at risk of flooding. NRD building locations were counted as flooded if the property point location intersected a flood depth exceeding $0.3 \mathrm{~m}$, based on the typical height of the property threshold. Key sites and infrastructure impacts were estimated as counts of NRD locations within flood areas, based on the building impact criteria. The road and rail network were the focus for the transport impact criteria based on intersections of flooding with the NRD transport layer. Transport links were deemed to be disrupted by flood water if intersected by flooding of depth $0.15 \mathrm{~m}$ or higher. This is a conservative estimate for roads becoming impassable or closed, based on a typical ground clearance for a small or family car. Transport routes are modelled as a network; the distance between junctions is used to indicate the length of the route affected. Key road transport routes are identified separately as trunk roads and motorways.

Processing of the impact criteria metrics was undertaken using ArcGIS and MapInfo and the results summarized for each $1 \mathrm{~km}$ cell in the study area.

\subsection{Measuring Impact Severity}

The SWF HIM considers risk across multiple impact criteria, which presents challenges with regard to alignment and comparison of the risk. To aid this, impact severities are standardised using the thresholds in Table 2. Initial thresholds were proposed based on interpretation of current FFC forecasting tools. Further validation and sensitivity testing is required before these values can be used in an operational setting. A value of 0 was attributed to cells that were not exposed to the SWF hazard.

\subsection{Aggregating Impact criteria results}

This paper follows Meyer et al. [21] in adopting a disjunctive Multi-Criteria Analysis approach to aggregate impact severity levels across impact criteria. This has similarities with the single threshold hotspot method proposed for local flood risk assessment by the EA [9]. Each $1 \mathrm{~km}$ cell was allocated the highest risk score of all contributing impact criteria. The disjunctive approach provides a simple and immediate focus in a time-critical forecasting situation. 


\begin{tabular}{|c|c|c|c|c|}
\hline & \multicolumn{4}{|c|}{ Impact Severity Level } \\
\hline Impact Criteria & Minimal (1) & Minor (2) & Significant (3) & Severe (4) \\
\hline Danger to Life (Count) & 0 & 40 & 200 & 300 \\
\hline Damage to Buildings & & & & \\
\hline - $\quad$ Residential (Count) & 0 & 5 & 30 & 100 \\
\hline - $\quad$ Non-Residential (Count) & 0 & 1 & 10 & 30 \\
\hline Denial of access to Key sites (Count) & - & 0 & 1 & 2 \\
\hline Denial of access to Infrastructure (Count) & 0 & 1 & 2 & 4 \\
\hline Disruption of Transport & & & & \\
\hline _ $\quad$ Trunk Roads and Motorways (m) & 0 & 150 & 500 & 1800 \\
\hline - $\quad$ Other Major Roads (m) & 0 & 500 & 1800 & - \\
\hline Railways (m) & 0 & 300 & 950 & - \\
\hline
\end{tabular}

Table 2. Impact thresholds proposed for the SWF HIM.

\subsection{Analysis of Impact Library against a forecast SWF event.}

The flood hazard component of the SWF HIM is produced by $\mathrm{CEH}$ using the $\mathrm{G} 2 \mathrm{G}$ distributed hydrological model along with ensemble rainfall forecasts from the Met Office as input. In the G2G model, an estimate is produced of the surface runoff generated from rainfall within each $1 \mathrm{~km}$ grid cell at 15 minute intervals. Spatial datasets on landscape properties (land-cover, soil, terrain slope) supporting the model formulation and continuous accounting of soil moisture within $\mathrm{G} 2 \mathrm{G}$ control runoff generation [7, 3]. The Met Office Global and Regional Ensemble Prediction System MOGREPS [22] provides ensemble rainfall forecasts for input into the $\mathrm{G} 2 \mathrm{G}$ model. At the UK regional scale, the forecasts have a spatial resolution of $2.2 \mathrm{~km}$.

G2G surface runoff information for $1 \mathrm{~km}$ cells over a 24-hour forecast window is produced using a 12-member rainfall forecast ensemble updated four times per day. The runoff information needed by the impact library is obtained by calculating the maximum rainfall accumulation of a given duration over the forecast window and associating this with a return period exceedance by reference to the uFMfSW. This return period information is used in the Impact Library to produce a unique map of flood impacts for each criteria. This process is replicated for each ensemble member to produce 12 impact maps from which the likelihood of impact can be determined for each $1 \mathrm{~km}$ cell.

\subsection{Summary of results and measurement of risk}

The $1 \mathrm{~km}$ grid cell impact layers are aggregated into reporting areas using county/local authority boundaries to provide a more meaningful summary for rapid emergency response. Summary impacts are derived using a threshold calculated using Equation 1.

$$
n=A\left(\frac{p}{100}\right)
$$

where $n$ is the number of cells within a county/local authority that are required to exceed a given impact severity (minor, significant or severe) and $A$ is the area $\left(\mathrm{km}^{2}\right)$ of the reporting area that has the potential to be subject to impacts of severity minor or greater. The derivation of $A$ excludes areas where no impacts were modelled within any of the impact criteria. These are typically rural areas such as farmland and national parks and have few built assets. This provides consistency of the summary across reporting areas of different sizes and impact potential. The value of $p$ determines the minimum percentage of cells within a reporting area that need to be exceeded for a given impact severity. For the results presented here, $p$ is assigned a value of 1 , which reflects the $99^{\text {th }}$ percentile of the reporting area. The minimum value of $n$ is set at 1 .

The SWF risk for each reporting area is derived by summarising the impact severity scores across the ensemble data. For each reporting area, the 12 final impact outputs are analysed via a histogram with thresholds defined by the 4 levels of impact severity. The histogram is used to measure the likelihood of exceeding each severity, represented by a cumulative distribution, which is then used to determine a row position for each impact severity on the Flood Risk Matrix (Figure 2). The highest level of overall flood risk attained is used to represent the risk. 


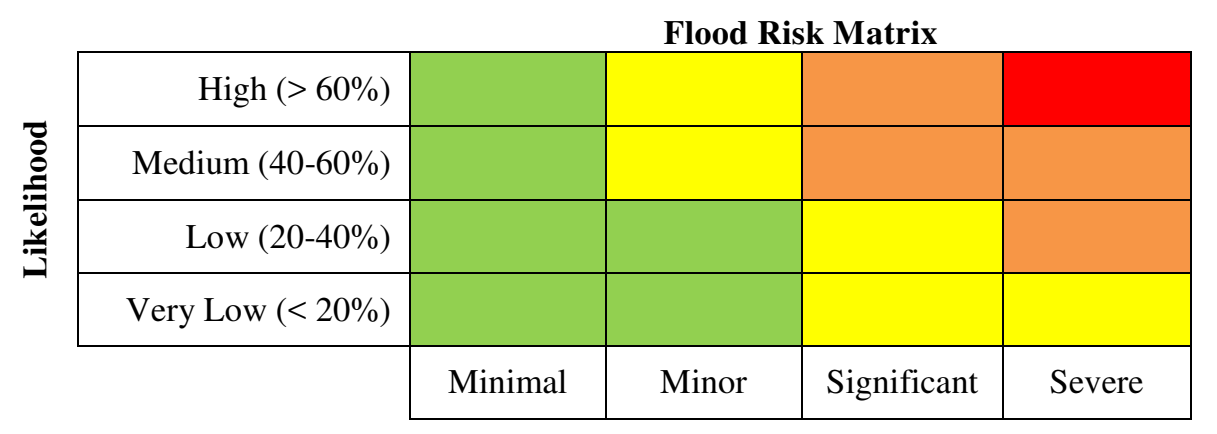

Potential Impacts
Overall Flood Risk

\begin{tabular}{|c|c|}
\hline High & \\
\hline Medium & \\
\hline Low & \\
\hline Very Low & \\
\hline
\end{tabular}

Figure 2. Flood Risk Matrix used by the FFC (adapted from FFC, 2013)

\section{Results}

\subsection{County level summaries}

Figure 3 illustrates county/local authority risk summary results for a $0-24 \mathrm{hr}$ forecast window, for 8 time-steps over a 2-day period. Colours represent risk, based on the Flood Risk Matrix (Figure 2). The SWF HIM county summaries indicate that the key SWF risks appear on 27 June $(19: 15)$ and 28 June (00:15 and 07:15). On 27 June (19:15) a Medium risk (Amber) is allocated to Darlington and County Durham based on a medium likelihood of a significant impact. The 28 June (00:15) presents Medium risks for Northumberland (high likelihood of a significant impact) and Tyne and Wear (medium likelihood of a significant impact). The 28 June (07:15) assigns Medium risk to Northumberland (medium

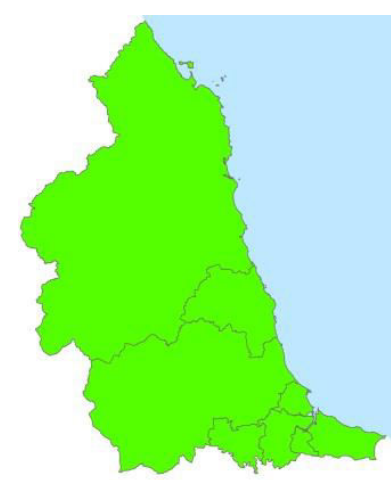

00:15 27 June

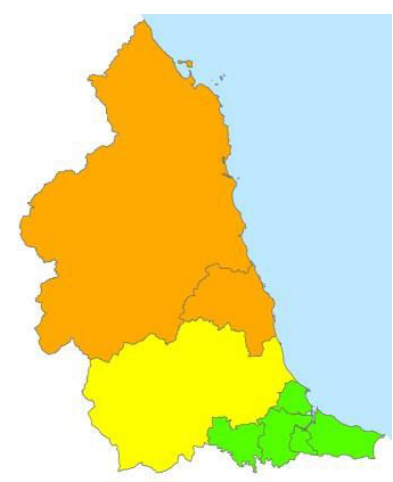

00:15 28 June

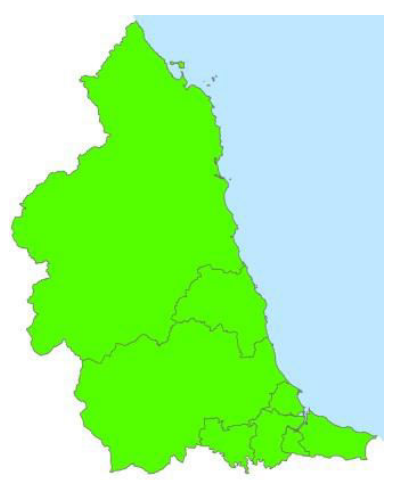

07:15 27 June

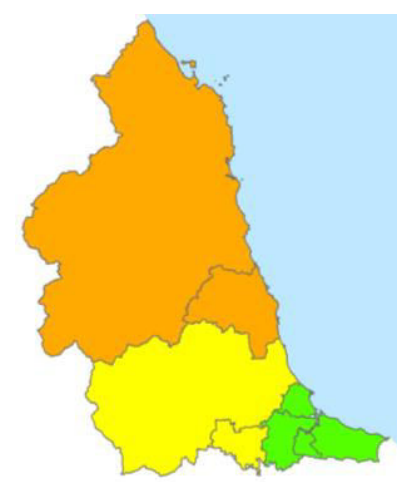

07:15 28 June likelihood of a significant impact) and Tyne and Wear (high likelihood of a significant impact). For these three forecasts, low risk (Yellow) is also allocated to Northumberland, Tyne and Wear, and County Durham.

Figure 4 presents SWF HIM histogram data for the 0-24 hour time period, for the 2 day forecast period limited to the 4 counties in the case study area with risks of low and above. The values in the table are counts of ensemble members (maximum 12) that exceed each impact severity, for each forecast step. The colours represent the risk based on the Flood Risk Matrix. An alternative visualisation of the risk information in Figure 4 is provided in Figure 5 for the county of Tyne and Wear, providing an immediate visual representation of the composition of risk. Columns represent time-steps and rows represent the impact severity. Bubble size represents the number of ensembles within each impact severity. The colour of the bubble represents the risk.

As well as showing how the situation changes over
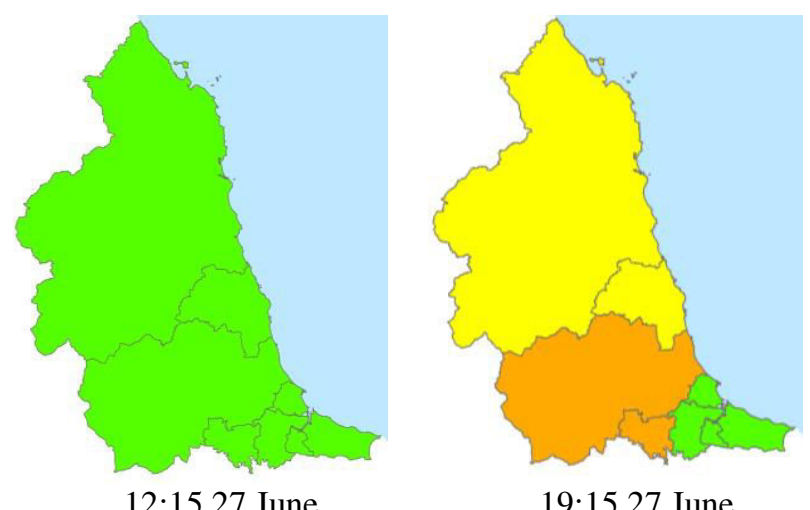

19:15 27 June

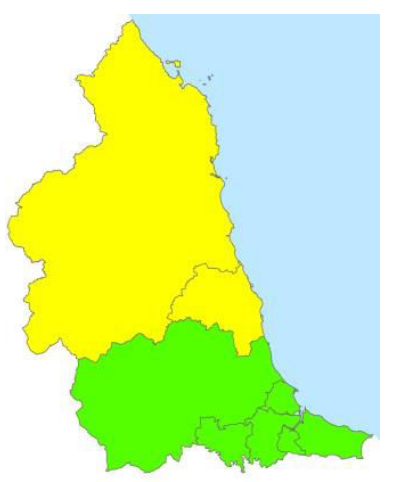

12:15 28 June

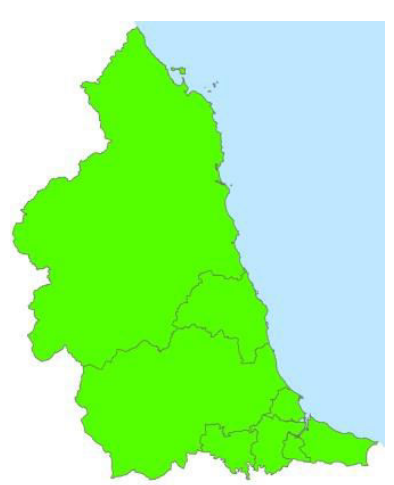

19:15 28 June

Figure 3. County-level summaries for the case study across the three days of forecasted rainfall. Colours indicate levels of risk. Green $=$ Very Low, Yellow $=$ Low, Amber $=$ Medium . 


\begin{tabular}{|c|c|c|c|c|c|c|c|c|c|c|c|c|c|c|c|c|}
\hline \multirow[b]{2}{*}{$\begin{array}{l}\text { Forecast } \\
\text { Step } \\
\text { (June } \\
\text { 2012) }\end{array}$} & \multicolumn{4}{|c|}{ Darlington } & \multicolumn{4}{|c|}{ Durham } & \multicolumn{4}{|c|}{ Northumberland } & \multicolumn{4}{|c|}{ Tyne and Wear } \\
\hline & 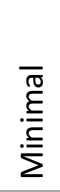 & 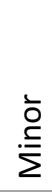 & 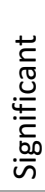 & 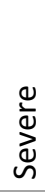 & 苞 & $\stackrel{\grave{c}}{\stackrel{亠}{\Sigma}}$ & 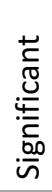 & & 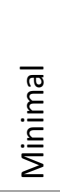 & 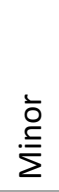 & 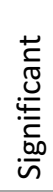 & & 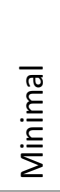 & 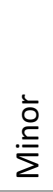 & 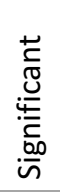 & 亗 \\
\hline $27^{\text {th }} 00: 15$ & 12 & 0 & 0 & 0 & 12 & 0 & 0 & 0 & 12 & 0 & 0 & 0 & 12 & 0 & 0 & 0 \\
\hline $27^{\text {th }} 07: 15$ & 12 & 0 & 0 & 0 & 12 & 0 & 0 & 0 & 12 & 0 & 0 & 0 & 12 & 0 & 0 & 0 \\
\hline $27^{\text {th }} 12: 15$ & 12 & 0 & 0 & 0 & 12 & 0 & 0 & 0 & 12 & 0 & 0 & 0 & 12 & 0 & 0 & 0 \\
\hline $27^{\text {th }} 19: 15$ & 12 & 6 & 5 & 0 & 12 & 8 & 5 & 0 & 12 & 10 & 3 & 0 & 12 & 5 & 3 & 0 \\
\hline $28^{\text {th }} 00: 15$ & 12 & 0 & 0 & 0 & 12 & 3 & 3 & 0 & 12 & 12 & 10 & 1 & 12 & 7 & 6 & 1 \\
\hline $28^{\text {th }} 07: 15$ & 12 & 4 & 2 & 0 & 12 & 8 & 4 & 0 & 12 & 10 & 7 & 0 & 12 & 8 & 8 & 1 \\
\hline $28^{\text {th }} 12: 15$ & 12 & 0 & 0 & 0 & 12 & 0 & 0 & 0 & 12 & 6 & 1 & 0 & 12 & 2 & 1 & 0 \\
\hline $28^{\text {th }} 19: 15$ & 12 & 0 & 0 & 0 & 12 & 0 & 0 & 0 & 12 & 0 & 0 & 0 & 12 & 0 & 0 & 0 \\
\hline
\end{tabular}

Figure 4. Histogram information detailing the count of ensembles that exceed each level of impact severity over time, for 4 counties. Colours indicate the risk rating based on the Flood Risk Matrix.

time, the visualisations in Figure 4 and Figure 5 highlight that the same levels of risk can be derived from different combinations of likelihood and impact, when based on the Flood Risk Matrix. For example, the Low (yellow) risk for Tyne and Wear for the 27 June 19:15 forecast is either the result of a medium likelihood minor impact, or a low likelihood significant impact. The implication for forecasters and responders is significant as the required response may be very different. To add further complication, the same level of risk could be the result of very different spatial patterns of impact. Consequently, the $1 \mathrm{~km}$ summary data provided by the SWF HIM is invaluable for deeper analysis of the risk.

\section{$4.21 \mathrm{~km}$ cell summaries}

The SWF HIM $1 \mathrm{~km}$ cell summaries are calculated as the maximum impact severity by criteria across the ensemble rainfall forecast. Figure 6 presents the $1 \mathrm{~km}$ cell summaries for the 28 June 2012 00:15 forecast, for the 024 forecast window, centred on the County of Tyne and Wear. The maximum of all criteria is also included.

The main impacts modelled are concentrated over the urban area of Newcastle upon Tyne. Property is shown to be the most active criteria for this forecast with impacted cells modelled across the area, including 4 red (Severe impact) cells and 28 amber (Significant). These red cells represent large numbers of buildings at risk and cover large industrial estates and dense town centres. The population criteria also contribute a red cell to the overall maximum summary. This is identified as a school population within an area of flood hazard. Transport impacts are modelled as Minor or Significant, with trunk routes affected. Key Sites and Infrastructure are modelled within a single cell.

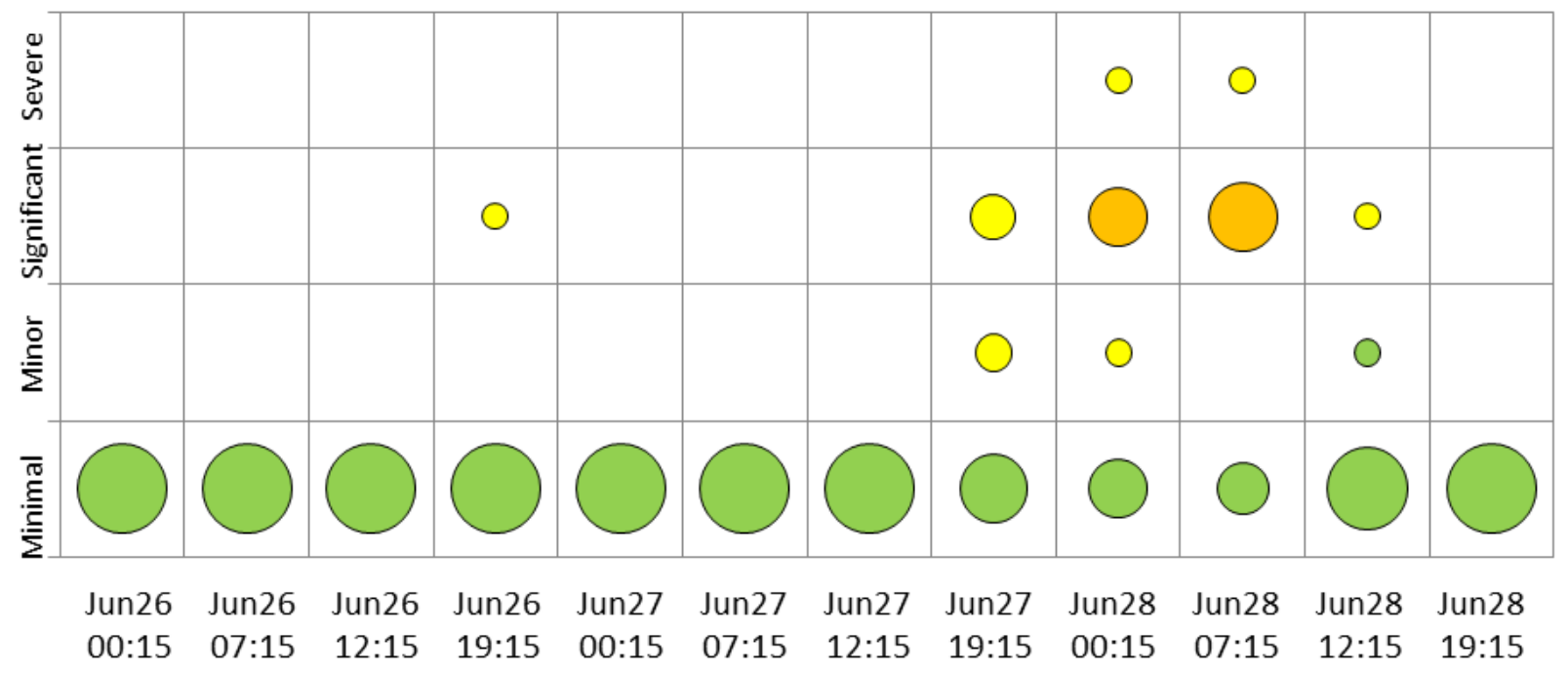

Figure 5. Flood risk histograms over the case study flood event for the county of Tyne and Wear. Columns represent time-steps. Rows represent impact severities. Size and location of bubbles indicates the number of ensemble members recording a given impact severity. The colour of the bubbles indicates the risk level. 
Maximum impact severity over 12 ensemble members for impact criteria

28 June 2012 00:15

Impact Severity

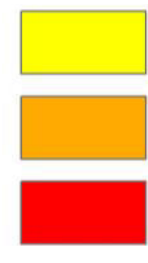

Minor

Significant

Severe

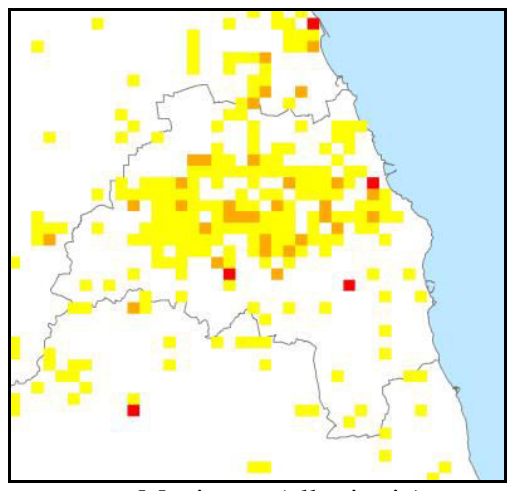

Maximum (all criteria)

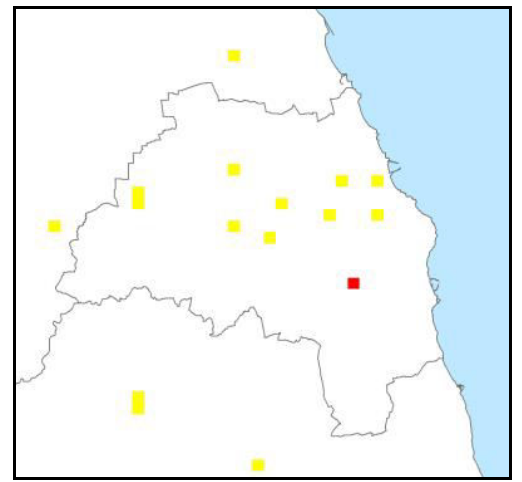

Population

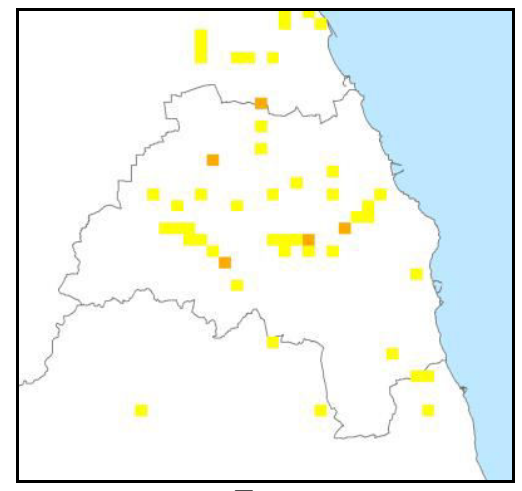

Transport

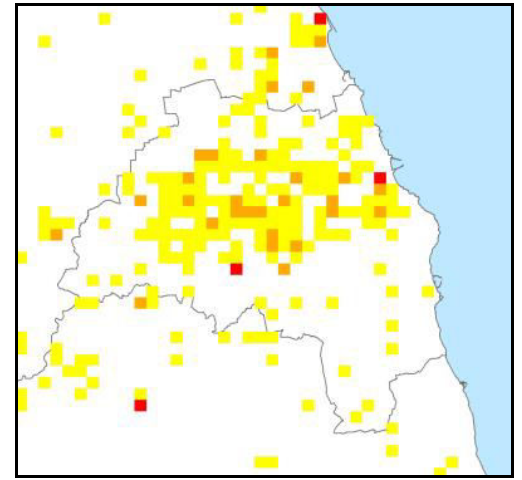

Property

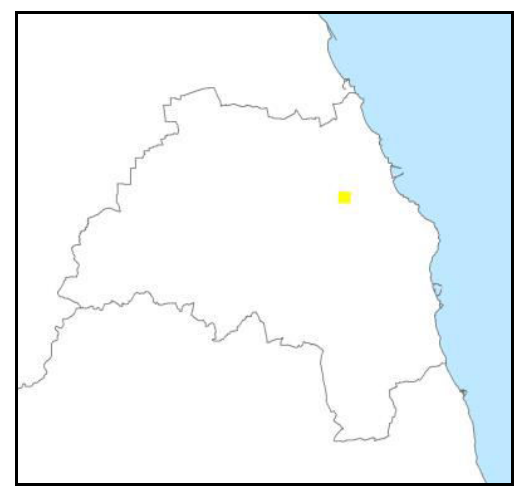

Key Sites and Infrastructure

Figure 6. Individual impact criteria and total summaries (maximum scores) at $1 \mathrm{~km}$ cell level during the $28 \mathrm{June} 00: 15$ time-step.

\section{Discussion}

The proof-of-concept SWF HIM presented in this paper demonstrates a novel approach for the modelling of SWF impacts that has potential uses in an operational context. The linking of rainfall forecasts to static information on flood risk via $\mathrm{G} 2 \mathrm{G}$ means that much of the detailed processing can be undertaken in advance, with potential benefits in terms of computational resources and timely delivery in a forecasting situation. The pre-processing approach is implemented here through the creation of the Impact Library which stores information on the potential impacts ready for use in the full SWF HIM. Further, the $1 \mathrm{~km}$ resolution of the impact maps can provide new insights for forecasters including the capability to assess localised impact severities and evaluate the overall coverage of flooding in much greater detail. The different impact criteria offer a more comprehensive picture of the risk. The use of the SWF HIM and Impact Library data in further contexts might also be explored. Potential applications include scenario planning and post-event analysis of case study events.

Further testing and validation of the SWF HIM is essential to further development and this is an area of active research. In particular, there is a requirement to better understand threshold sensitivities throughout the HIM. This will help to understand the sensitivities in the approach and highlight uncertainties within the model. There may also be value in assessing the relationships between the impact criteria to ensure that the summary output information is balanced and is representative of all criteria. The case study results presented here show promise for analysing both county and $1 \mathrm{~km}$ cell level risk, and have some alignment with the recorded events. Further validation against case study events such as this is planned to evaluate the effectiveness and provide evidence for further refinement.

Continued development of the impact metrics is also required, taking advantage of recent applications and research within this area. Vulnerability is a key element as it defines how individual receptors react to the flood hazard. The approach in this study has considered the specific vulnerability of different population groups. However, the literature widely cites the alternative approach of vulnerability index development based on multi-criteria data (e.g. The UK-based Social Flood Vulnerability Index [23]). In particular, this may be a useful addition for capturing the social and psychological impacts highlighted above that are outside the basic group vulnerability definitions implemented. Integrating these approaches into an operational environment raises questions surrounding which data would be required to develop indicators for stress and anxiety and also the confidence to which these could be mapped and modelled. As an alternative, monetary and economic measurements could be used in preference of human impacts [12].

Communication of SWF HIM results to end-users is another important consideration. The combination of impact criteria and ensemble forecasting over multiple time-steps creates a rich but potentially unwieldy set of outputs. Managing this information effectively is essential if it is to be successfully exploited for operational use. Metadata, explanatory material and 
training of users will also be important to ensure that the outputs of the SWF HIM are understood, and the extent of its capabilities known.

The Impact Library concept described in this paper has potential further application outside of SWF. Static information on hazard susceptibility for other natural hazards such as landslides or other types of flooding might be used for further risk forecasting. This is currently being explored within the NHP.

\section{Conclusions}

In addressing the demand for improved risk-based SWF warning systems, and in answering calls by OchoaRodriguez et al. [5] and Parker et al. [6] to improve the spatial and temporal resolution of these systems, this paper has detailed an approach to develop an improved forecasting capability for evaluating the potential impacts of SWF for the FFC. The modelling of impacts alongside the flood hazard has potential benefits for forecasters, providing a fuller picture of the risk. The pre-calculation of the impact information makes available a rich database of information that can be more immediately evaluated within a rapidly changing forecasting situation. Further development and testing is required before the tool can be used operationally. Future phases of this work will focus on validating SWF HIM outputs against independent observed sources of data, conducting sensitivity analysis to identify key variables and limitations, and a general refinement of impact measurements, following the current state of science.

\section{Acknowledgment and Disclaimer.}

This paper and the work it describes was funded by the Flood Forecasting Centre. The Health and Safety Laboratory is the commercial arm of the Health and Safety Executive; the paper's contents, including any opinions and/or conclusions expressed, are those of the authors alone and do not necessarily reflect HSE policy.

\section{References}

1. EU (2007). Directive 2007/60/EU of the European Parliament and of the Council of 23 October 2007 on the assessment and management of flood risks, Official Journal of the European Union, 2007.

2. Cabinet Office (2008). The Pitt Review: lessons learned from the 2007 floods. London, Cabinet Office.

3. Cole S. J., Moore R. J., Aldridge T., Lane A. and Laeger, S. (2013). Real-time hazard impact modelling of surface water flooding: some UK developments. International Conference on Flood Resilience: Experiences in Asia and Europe, Exeter, UK, 5-7 Sept. 2013, 67-68.

4. Golding B. W., Ballard S. P., Mylne K., Roberts N., Saulter A., Wilson C., Agnew P., Davis L. S., Trice J., Jones C., Simonin D., Li Z., Pierce C., Bennett A., Weeks M. and Moseley S. (2014). Forecasting capabilities for the London 2012 Olympics. Bull. Amer. Meteor. Soc., 95, 883-896.

5. Ochoa-Rodriguez S., Thraves L. and Johnson A. (2013) Surface water flood warnings in England: An overview, assessment and recommendations based on survey responses and workshops, In: Butler, D., Chen, A.S., Djordjević, S. and Hammond, M. (eds.), Proc. Int. Conf. on Flood Resilience: Experiences in Asia and Europe (ICFR 2013), University of Exeter.

6. Parker D. J., Priest S. J. and McCarthy S. S. (2011) Surface water flood warnings requirements and potential in England and Wales, Applied Geography, 31(3), 891-900.

7. Moore R. J., Cole S. J., Bell V. A. and Jones D. A. (2006). Issues in flood forecasting: ungauged basins, extreme floods and uncertainty. In: I. Tchiguirinskaia, K. N. N. Thein \& P. Hubert (eds.), Frontiers in Flood Research, 8th Kovacs Colloquium, UNESCO, Paris, June/July 2006, IAHS Publ. 305, 103-122.

8. Price D., Hudson K., Boyce G., Schellekens J., Moore R. J., Clark P., Harrison T., Connolly E. and Pilling, C. (2012). Operational use of a grid-based model for flood forecasting. Proc. ICE - Water Manage., 165, 65-77.

9. EA (2014) Framework and tools for local flood risk assessment. Science Report SC070059/R3, Environment Agency, Bristol, UK.

10. Vinet F., Lumbroso D., Defossez S. and Boissier L. (2012). A comparative analysis of the loss of life during two recent floods in France: the sea surge caused by the storm Xynthia and the flash flood in Var. Natural Hazards, 61, 1179-1201.

11. HR Wallingford, Middlesex University Flood Hazard Research Centre and Risk \& Policy Analysts Ltd (2005). Flood Risks to People Phase 2: The Risks to People Methodology, Defra / Environment Agency Report: FD2321/TR1.

12. Meyer V., Becker N., Markantonis V., Schwarze R., van den Bergh J. C. J. M., Bouwer L. M., Bubeck P., Ciavola P., Genovese E., Green C., Hallegatte S., Kreibich H., Lequeux Q., Logar I., Papyrakis E., Pfurtscheller C., Poussin J., Przyluski V., Thieken A.H. and Viavattene C. (2013). Review article: Assessing the costs of natural hazards - state of the art and knowledge gaps. Natural Hazards and Earth System Sciences, 13(5), 1351-1373. doi: 10.5194/nhess-13-1351-2013.

13. Penning-Rowsell E., Johnson C., Tunstall S., Tapsell S., Morris J., Chatterton J. and Green C. with contributions from Wilson T., Koussela K. and Fernandez-Bilbao A. (2013). The Benefits of Flood and Coastal Risk Management: A Handbook of Assessment Techniques, Middlesex University Press.

14. Kazmierczak A. and Kenny C. (2011). Risk of flooding to infrastructure in Greater Manchester. EcoCities project University of Manchester, Manchester, UK.

15. Pikusa E. (2015). The National Emergency Risk Assessment Guidelines: The Bumpy Road to National Consistency. Floodplain Management Association National Conference, 19-22 May 2015, Brisbane, Australia. 
16. EA (2012) Flooding 2012 summary events - England and Wales. Environment Agency.

17. Newcastle City Council (2013) Summer 2012 Flooding in Newcastle upon Tyne: A report on the experiences of residences and non-residential property managershttp://www.newcastle.gov.uk/sites/drupalnc c.newcastle.gov.uk/files/wwwfileroot/environment/en vironment/microsoft_word__summer_2012_flooding_report_-_final_july_2013.pdf . Last accessed 03/07/2015.

18. EA (2014). The updated Flood Map for Surface Water (uFMfSW) Property Points dataset: July 2014.

19. Smith G. and Fairburn J. (2008). Updating and improving the National Population Database to National Population database 2. HSE Research Report RR678.

20. EA (2010). National Receptor Dataset: guidance for Environment Agency Staff and professional Partners. Environment Agency.

21. Meyer V., Haase D and Scheuer S. (2007). GIS-based Multicriteria Analysis as Decision Support in Flood Risk Management, FLOODsite Report T10-07-07.

22. Met Office (2014). The Met Office ensemble system. (MOGREPS)

http://www.metoffice.gov.uk/research/areas/dataassimilation-and-ensembles/ensembleforecasting/MOGREPS. Last Accessed 29/05/2015.

23. Tapsell S. M., Penning-Rowsell E. C. Tunstall, S. M. and Wilson T. L. (2002). Vulnerability to flooding: health and social dimensions. Philosophical transactions of the Royal Society A 360, 1511-1525. 